\title{
Going Global
}

\author{
Peter Black, Editor-in-Chief ${ }^{凶}$
}

Soc Int Urol J. 2020;1(1):3

The SIU Journal has officially arrived! We are proud to present Volume 1, Issue 1-the starting point for all journals, big and small. For the SIUJ this is the first step on the road to becoming part of the global urologic fabric, delivering high quality urologic research to an audience around the world.

The SIU has a long history of partnering with some of the key urologic journals, including BJU International, Urology, and, most recently, the World Journal of Urology. These have always been valuable collaborations. In recent years, however, the SIU has experienced enormous growth, and, with over 10000 members currently, the time has come to launch our own journal that we can tailor to the needs of our truly global membership.

Although the publishing space for urologic journals has become increasingly crowded, the growing number of good quality publications from around the world accommodates this expansion. We hope to reflect the character and spirit of the SIU in the Journal, and to attract both readers and authors from across the global urologic community, starting with but not limited to our own membership. We will introduce regular features such as "Urology Around the World" to showcase global urologic practices and experiences. We have structured our editorial board to be representative of all regions of the world, and have introduced regional editors specifically to champion the SIUJ in their respective regions-but also to champion their regions in the make-up of the SIUJ. We aim to be nimble and responsive so that we can adapt to the changing needs of our members. We want our members to value the SIUJ, and to identify the SIUJ as their own. We believe that the combined energy invested by the members of the editorial board is central to creating a successful journal.

A critical feature of the SIUJ is open access. This open access will come at no cost to members, and only a nominal cost to non-member authors in a way that encourages non-members to sign up for membership. We are sending a very clear signal with this policy. We want universal access to the content of SIUJ, which is especially important for urologists in the developing world. Open access also increases the reach and impact of articles, which is the ultimate goal of academic publishing and serves the needs of the authors. Furthermore, all the hard work of the urologists and other health care providers who are writing and reviewing the manuscripts submitted to the SIUJ will benefit the urologic community and not the coffers of the publisher. With this in mind, we will institute rigorous peer review at the highest standards.

We are particularly pleased in our first issue of the SIUJ to be able to offer a series of review articles on stateof-the art use of biomarkers in urologic oncology. These articles are summaries of full chapters written for the 1st International Consultation on Urologic Disease (ICUD) World Urologic Oncology Forum (WUOF) Consultation consultation on Molecular Biomarkers in Urologic Oncology, led by Yair Lotan, Nathan Lawrentschuk, and Jack Schalken, that will be published later this year.

Please join me and the entire SIUJ editorial team in embracing our new Journal and making it a lasting success! 